Anton Duisters

\title{
HET KIJKGLAS
}

\section{NEGENTIENDE-EEUWSE FANTASIEËN OVER TELEVISIE}

\section{Inleiding}

'I'll tell you all my ideas about Looking-glass House. First, there's

the room you can see through the glass - that's just the same as our drawing-room, only the things go the other way'.

In Through the Looking Glass, dat Lewis Carroll in I87i schrijft als vervolg op het succesvolle Alice's Adventures in Wonderland (I865), maakt Alice het zwarte huiskatje deelgenoot van haar fantasieën over 'Looking-glass House', ${ }^{2}$ het huis dat zich achter het glas van de spiegel bevindt. In Carrolls absurdistische wereld krijgt Alice ook echt de kans om de oversteek naar die andere wereld te maken; ze stapt door het spiegelglas en belandt in een virtuele werkelijkheid. Tijdens haar avonturen aan die andere kant van de spiegel blijven oog en lichaam dus aan elkaar gekoppeld. Alice bekijkt de wereld niet op afstand via een televisiescherm alsof ze er echt aanwezig is, maar ze maakt ook daadwerkelijk de stap in die andere wereld. Het is belangrijk te beseffen dat Carroll zijn boek schrijft in een periode dat er in uitvinderskringen misschien wel voorzichtig gedacht wordt over televisie, maar waarin dit nog niet echt is doorgedrongen tot een brede laag van de bevolking.

Toch staat de negentiende eeuw te boek als een tijdperk waarin de waarnemende mens opvallend verandert. Veel mediageschiedenissen leggen dit omslagpunt aan het eind van de negentiende eeuw (I870-I880); ze koppelen dit nieuwe kijken aan impressionisme, fotografie en film. Jonathan Crary onderschrijft deze visie niet. In zijn boek Techniques of the Observer stelt hij dat deze transformatie al aan het begin van de negentiende eeuw plaatsheeft. Dan komen er namelijk tal van nieuwe optische amusementsproducten op de markt die er alleen op gericht zijn de fantasie van de gebruiker te prikkelen. ${ }^{3}$ Crary stelt dat het oog zich in deze periode losmaakt van het lichaam en dat deze wijziging in waarnemen de fundering vormt waarop uiteindelijk film en televisie voortbouwen.

In tegenstelling tot Crary, die uitgaat van een breuk in de visuele cultuur, betoog ik in dit essay dat binnen de populaire cultuur het idee van het gelijktijdig over afstand zien zonder dat de kijker lijfelijk ter plaatse aanwezig is, pas eind 
“O, Kitty, wat zou het leuk zijn als wij toch eens een keer het Spiegelhuis in konden! ' $k$ Weet zeker dat daar o! zo mooie dingen zijn! Laten we doen of we er op de een of andere manier binnen kunnen komen." Illustratie: John Tenniel.

Bron: L. Carroll, De avonturen van Alice in

Wonderland \& Achter de spiegel. Vert. Nicolaas Matsier.

Amsterdam, Van Goor 1994, p. 139-140

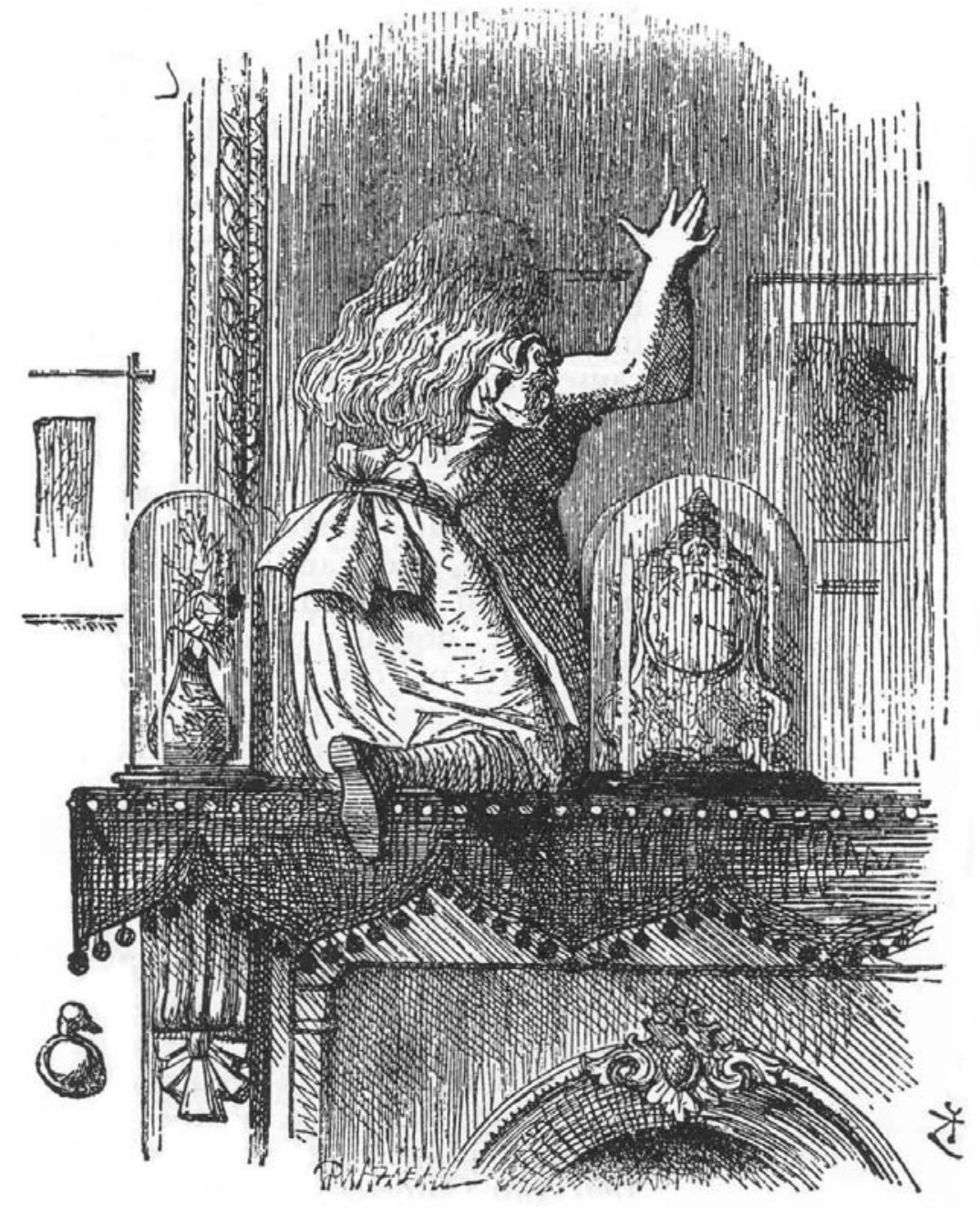

negentiende eeuw onderdeel begint uit te maken van de fictionele literatuur; het televisieconcept maakt vóór de introductie van de telefoon in I 876 en de innovaties die hierop volgen geen serieus onderdeel uit van de collectieve fantasie. Eerst schets ik kort de verschillende visies op de oorsprong van het televisietoestel en ga ik dieper in op de 'nieuwe waarnemer' van Johathan Crary. Daarna baken ik het onderzoeksgebied af door het begrip televisie duidelijk te definiëren om tenslotte via literaire bronnen voorzichtig aan te tonen dat er in de negentiende eeuw ook binnen de fantasie van schrijvers een duidelijke kentering plaatsheeft: de belichaamde blik maakt plaats voor de onafhankelijkheid van het oog waardoor het mogelijk wordt over grote afstand te zien zonder zelf daadwerkelijk aanwezig te zijn. Op basis van deze bronnen situeer ik deze trans- 
formatie niet in het eerste deel van de negentiende eeuw, maar veel meer in het tweede deel.

Mijn veronderstelling is gebaseerd op een klein aantal bronnen uit de fantasieliteratuur dat een willekeurige dwarsdoorsnede vormt van de negentiendeeeuwse productie: de gebroeders Grimm, Walter Scott, Hans Christian Andersen, Jules Verne, Oscar Wilde, Albert Robida, Camille Flammarion en Herbert G. Wells. De voorzichtige conclusie aan het eind van dit essay moet dan ook worden gezien als een aanzet tot discussie en tot een grondiger literatuuronderzoek.

\section{Televisiegeschiedenis}

'When at last colour photography has been achieved, and when a phonograph has been added to that, then movement and speech will be caught simultaneously, recorded simultaneously and reproduced simultaneously with rigorous accuracy, that is to say life itself. (...) Why shouldn't it be capable of giving us life itself. ${ }^{4}$

Zo jubelt een journalist van Le Magasin Pittoresque in zijn verslag over de eerste filmvertoning van de gebroeders Lumière op 2I maart I895. De broers vertonen tijdens de Société pour l'encouragement de l'industrie nationale in Parijs de film LA SORTIE DES US IN ES LU M İ̀ RE (Frankrijk: Auguste \& Louis Lumière, I895) en de nieuwe vinding krijgt veel aandacht in de Franse pers. Opvallend is dat de journalisten in hun berichtgeving vaak verwijzen naar 'het echte leven'.

In veel mediageschiedenissen vormt de eerste vertoning van een film voor een betalend publiek (december 1895 ) het begin van een nieuwe beeldcultuur die uiteindelijk tot de televisie leidt. ${ }^{6}$ Toch twijfelen filmwetenschappers steeds vaker aan deze lineair voorgestelde mediaontwikkeling. De tijdgeest van de negentiende eeuw ademt namelijk iets heel anders uit dan dat wat film vertegenwoordigt; iets wat ook tussen de regels te lezen is in de uitspraak in Le Magasin Pittoresque. 'Why shouldn't it be capable of giving us life itself?' Niet de vertoning van filmbeelden die elders zijn geschoten, maar het gelijktijdig meebeleven van gebeurtenissen zonder daar lijfelijk bij aanwezig te zijn, is een typische negentiende-eeuwse utopie; mensen verlangen ernaar hun blikveld te verruimen. Het is dan ook een periode van technische innovaties op het gebied van communicatie over afstand (telefonie, telegrafie) en optische instrumenten (stereoscoop, ${ }^{7}$ phaenakistiscoop, ${ }^{8}$ fotografie). Film is misschien een product dat een illusie van realiteit en simultaneïteit oproept, maar creëert geen directe verbinding met een andere wereld; hij vormt slechts een werkelijkheid die onderdeel uitmaakt van de fantasie. ${ }^{9}$

William Uricchio is ervan overtuigd dat niet film, maar televisie aan het eind van de negentiende eeuw onderdeel uitmaakte van de culturele verbeelding. 
'Kijkt men (...) naar de laat-negentiende-eeuwse cultuur in meer algemene zin: naar de telefoon, naar de ideeën die door elektriciteit werden gegenereerd, naar de fantasieën over nieuwe media, dan ontkomt men niet aan de indruk dat er op deze terreinen veel effectiever werd geanticipeerd op simultaneiteit, een simultaneiteit die de cinema hooguit kon simuleren, maar niet leveren.'

Film is in zijn optiek dus niet een vernieuwend of radicaal ander medium, maar 'een technologisch compromis, een omweg' . ${ }^{\text {Io }}$ Uricchio wijst op het octrooiregister. Daarin stonden destijds al media beschreven waarvan niet alleen beeld en geluid kenmerkende elementen waren, maar ook simultaneïteit (zoals de Nipkow-schijf van Paul Nipkow uit I884). Gelijktijdigheid was dan ook het toverwoord sinds de uitvinding van de telefoon (I876) ${ }^{\text {II }}$ die het mogelijk maakte 'live' te spreken met mensen die zich op een andere locatie bevonden. Dit prikkelde onmiddellijk de fantasie van wetenschappers en schrijvers over beeldtransmissie. Een van de schrijvers die het concept uitwerkte in een roman is Albert Robida. In Le vingtième siècle (I883) schetst hij de Parijse samenleving van I952/I953 met daarin verzonnen nieuwe vindingen. Een voor dit onderzoek interessant object is de telefonoscoop, waarmee je kunt zien en kunt horen. Maar hierover later meer in dit essay.

Dat de verwachtingshorizon van het filmpubliek niet echt bij film als medium lag, maar eigenlijk op televisie was gericht, blijkt volgens Uricchio ook uit het aanbod van de filmtheaters. In hun programma's bleven tot I 906 de nonfictionele onderwerpen de boventoon voeren; ze beantwoordden het meest aan de verwachting die de toeschouwer had van simultaneïteit. ${ }^{\mathrm{I2}}$

Uricchio's theorie krijgt veel navolging binnen de filmwetenschap. Jürgen Müller noemt film een 'unbefriedigender und begrenzter Um-Weg', ${ }^{\text {13 }}$ en Thomas Elsaesser stelt dat film wel eens een 'unwanted child' van de negentiende eeuw zou kunnen zijn. Het publiek wachtte op iets anders dan film.

'What it was imagining for its technotopic future was domestic television, and preferable two-ways television. And the Victorians not only dreamt of television. They were as hungry for instantaneity, for simultaneity and interactivity as we are today. ${ }^{\text {I4 }}$

Knut Hickethier schrijft dat de geschiedenis van televisie en film zich niet als één geschiedenis laat vertellen. Televisie is een van de grote droombeelden der mensheid; het vergroten van de waarneming, meer van de wereld zien. Hij schrijft: 'Fernsehen ist keineswegs (...) eine "nicht bestellte Erfindung”, sondern in ihm verwirklicht sich, wie auch in der Erfindung neuer Verkehrsmittel, ein alter Menschheitstraum nach Wahrnehmungserweiterung. ${ }^{\text {. }}$

Albert Abramson wijst er tenslotte op dat er een simpele reden is waarom televisie niet vóór film ontstond; de techniek om beelden live te verzenden en te 
ontvangen was eind negentiende eeuw nog onvoldoende ontwikkeld. Hierdoor werd film veel eerder aan het publiek gepresenteerd dan televisie. Maar hoe opwindend kijkers een filmvoorstelling ook vonden, toch was cinema niet het medium waarover mensen aan het eind van de negentiende eeuw fantaseerden, zo stelt Abramson.

'[Film] left a void; it was not instantaneous. The strip of film stood in the way. Thus men wondered what it would be like to have a device that could transmit its image at the very moment it was being picked up. ${ }^{\mathrm{i} 6}$

Ook Abramson benadrukt daarbij dat film en televisie niet dezelfde oorsprong hebben.

'The motion picture had arisen from a combination of photographic techniques combined with mechanical means for propelling a strip of light-sensitive emulsion through a camera; and after suitable processing, the developed strip of images being driven through a viewing device of one sort or another. Television evolved from the field of electrical communication, a direct descendant of the electrical telegraph, the telephone and finally "facsimile" or the transmission of still pictures. ${ }^{, 17}$

\section{Een niet-belichaamd kijken}

In zijn boek Techniques of the Observer stelt Jonathan Crary dat het waarnemen aan het begin van de negentiende eeuw verandert. Crary onderscheidt heel nadrukkelijk de termen waarnemer ('observer') en kijker ('spectator'). Hij maakt daarmee het passieve registreren van een toneelstuk of een serie schilderijen los van het waarnemen in haar actieve zingevingsrol, waarbij tijd- en cultuurgebonden conventies van invloed zijn. Crary schrijft: ‘[A]n observer is more importantly one who sees within a prescribed set of possibilities, one who is imbedded in a system of conventions and limitations. ${ }^{\text {, } 88}$ Een waarnemer beziet de wereld om zich heen door een structurerend filter dat de blik stuurt en begrenst. Deze culturele kadrering is bepalend voor het bevattingsvermogen. Crary betoogt nu dat dit bevattingsvermogen aan het begin van de negentiende eeuw wordt verruimd onder invloed van het grote aanbod aan nieuwe beeldproducten. Deze benaderen de toeschouwers op een volstrekt andere wijze dan zij gewend zijn. De innovaties op visueel gebied zijn er steeds meer op gericht om het oog dusdanig te manipuleren dat een gepresenteerde niet bestaande wereld als reëel wordt ervaren; het oog komt los te staan van het totale lichaam.

'[T]he most influential figurations of an observer in the early nineteenth century depended on the priority of models of subjective vision, in contrast to 
the pervasive suppression of subjectivity in vision in seventeenth- and eighteenth-century thoughts. ${ }^{\text {I9 }}$

Crary plaatst het verlichtingsdenken van de zeventiende en achttiende eeuw tegenover de romantische ideeën van de negentiende eeuw, ofwel het onbeperkt vertrouwen in de rede tegenover het benadrukken van de persoonlijke ervaring.

Voor Crary staat de camera obscura, als objectieve basis van een visuele waarheid, symbool voor het oude kijken. Het principe van deze 'donkere kamer' is eenvoudig. In een lichtdichte ruimte is een omgekeerd beeld te zien van een object dat zich erbuiten bevindt; deze projectie wordt veroorzaakt door licht dat via een zeer klein gaatje in de tegenoverliggende wand het verduisterde vertrek binnendringt. Kijkers kunnen steeds controleren of dat wat zij zien ook werkelijk buiten de ruimte te zien is. Visuele experimenten, zoals de stereoscoop en de fantasmagorie, ${ }^{20}$ die aan het begin van de negentiende eeuw opgeld doen en grote aantrekkingskracht uitoefenen op mensen, ondermijnen volgens Crary deze objectiviteit. De nieuwe technieken produceren een realistisch effect door de optische ervaring te abstraheren en reconstrueren. Het is een verandering van geometrisch zien naar fysiologisch zien; het bevattingsvermogen van de visuele wereld transformeert van een blik die direct is gekoppeld aan een lichamelijke aanwezigheid naar een manier van kijken die de capaciteiten van het menselijk oog optimaal benut en waarbij het aanwezig zijn van de rest van het lichaam niet meer van belang is. Het is een overgang van objectiviteit naar subjectiviteit. 'Vision is no longer subordinated to an exterior image of the true or the right. The eye is no longer what predicates a "real world". ${ }^{21}$

Het woord realisme krijgt bij de nieuwe beeldtechnieken een nieuwe inhoud; het is niet meer een directe weergave van de werkelijkheid waarbij de mens lichamelijk aanwezig is, maar een kunstmatige representatie die het oog zo manipuleert dat dit de voorgetoverde beelden als realiteit ervaart. Ook al lijkt een foto de waarnemer een realistische wereld te tonen, toch maakt deze reproductietechniek voor Crary duidelijk onderdeel uit van de nieuwe representatiewijze. De kijker wordt tijdelijk opgenomen in een andere werkelijkheid; hij komt als het ware vast te zitten in het beeld dat de foto hem toont. Dit ontwortelen van het zien, het uit zijn vertrouwde omgeving wegrukken van de blik, vindt volgens Crary plaats aan het begin van de negentiende eeuw, tussen i8io en ${\text { I } 840 . .^{22}}^{22}$

Het is grappig iets dat lijkt op dit geometrisch en fysiologisch zien terug te vinden in een van de legendarische avonturen van Karl Friedrich Hieronymus, baron Von Münchhausen. De schrijver Rudolf Raspe verzamelde er zeventien onder de titel Baron Von Munchhausen's Narrative of his Marvellous Travels and Campaigns in Rusia (I785). Een van de plekken die de leugenbaron aandoet, is de 


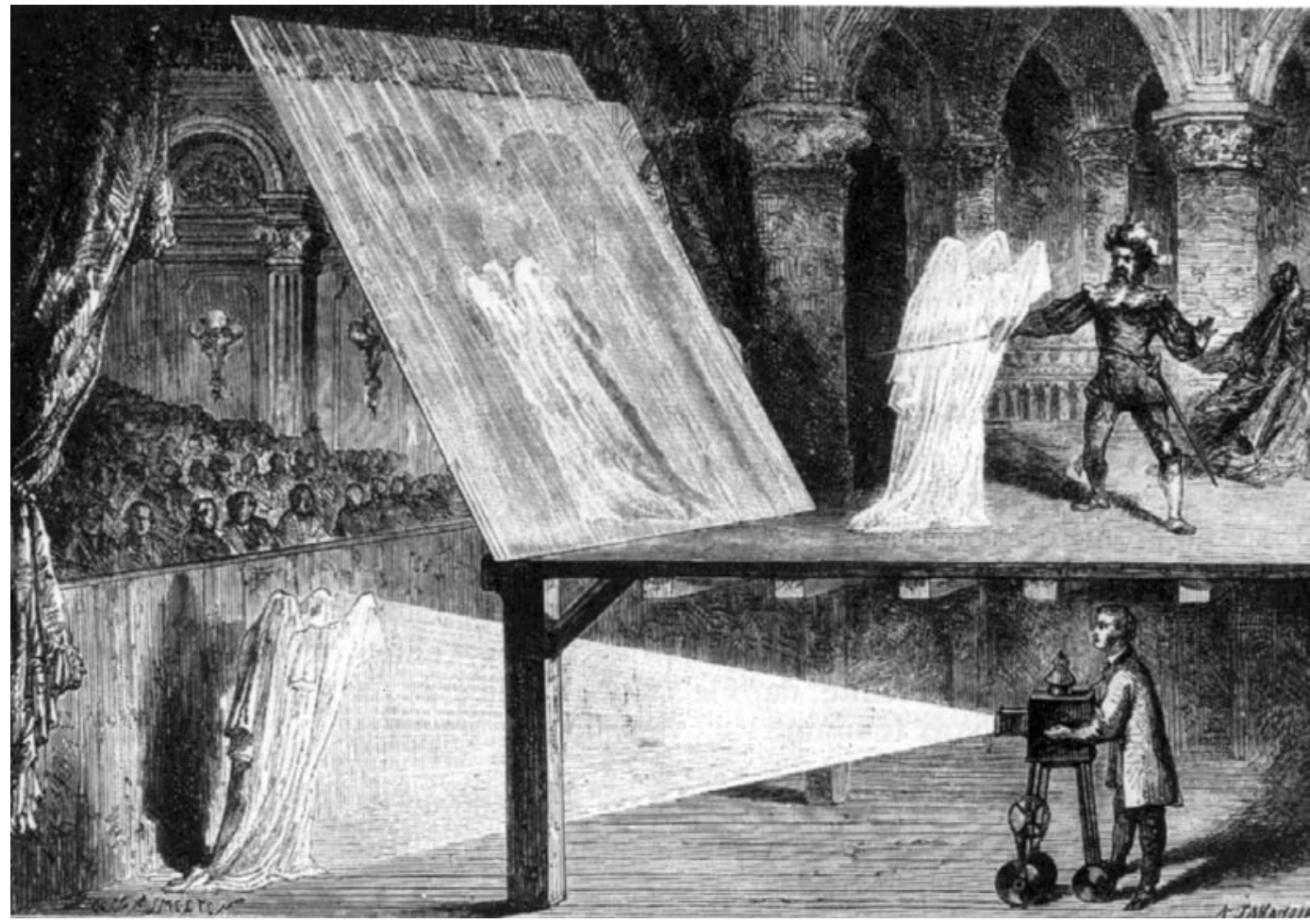

Fantasmagorische spookverschijning gecreëerd door een verrijdbare lichtbundel en een grote glasplaat. Bron: L. Sauvage, L'affaire Lumière, Parijs, Lherminier $1985, p .38$

maan. Hier ontmoet hij figuren die het hoofd onder de rechterarm dragen. Opmerkelijk is dat zij het hoofd niet altijd bij zich houden; zij kunnen het thuislaten of erop uitsturen om te spioneren. De hoofden kunnen zo 'ongemerkt (...) tegenwoordig zijn, en keeren op hun gemak terug naar huis, met een verhaal van het gene zij gezien en gehoord hebben. ${ }^{23}$ Bij deze maanbewoners blijft de band tussen de diverse zintuigen dus bewaard; het hoofd informeert de rest van het lichaam. Daarna beschrijft Von Münchhausen een 'modernere' groep maanbewoners bij wie de blik zich duidelijk heeft ontwikkeld tot een autonoom zintuig. Zij kunnen namelijk hun ogen uit het hoofd nemen, zonder dat dat invloed heeft op hun waarnemingsvermogen. De baron benadrukt dat ze even goed kunnen zien, 'of zij dezelven in hunne handen of in hunne hoofden hebben. ${ }^{24}$ Deze achtiende-eeuwse vertelling van de meesterfantast Von Münchhausen illustreert op inzichtelijke wijze Crary's ideeën over het oude en nieuwe zien. 


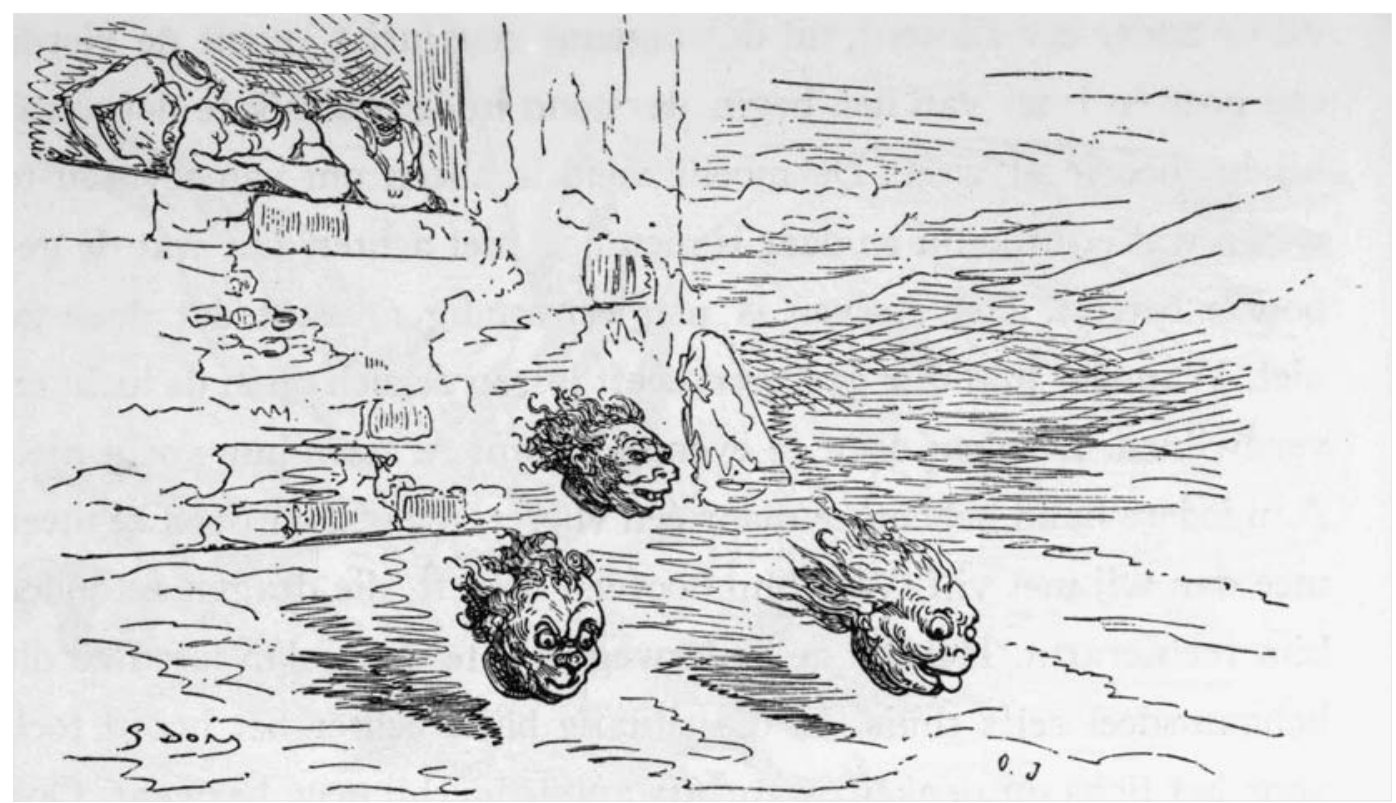

Maanbewoners sturen hun hoofden erop uit om op de hoogte te raken van interessante nieuwtjes. Illustratie: Gustave Doré. Bron: R.E. Raspe, De avonturen van Baron von Müchhausen, Amsterdam, Loeb 1989, p. 152

\section{Het televisiescherm}

Raspe schrijft het maanavontuur van de baron Von Münchhausen aan het eind van de achttiende eeuw, een periode waarin volgens Jonathan Crary het 'oude', belichaamde zien nog hoogtij viert. De waarneming verandert aan het begin van de negentiende eeuw, zo is zijn theorie, in een onbelichaamd zien waarbij het oog een autonome rol krijgt. Oorzaak van deze transformatie is voor Crary de introductie van allerlei nieuwe optische snufjes in de amusementsindustrie, die daar onmiddellijk veel succes hebben.

Ook binnen de fantasie literatuur lijkt zo'n overgang naar een ander blikveld (televisie) aanwijsbaar. Dit omslagpunt ligt echter niet aan het begin van de negentiende eeuw, ook al doet Raspes maanverhaal anders vermoeden, maar in de periode na I876. In dat jaar presenteert Alexander Graham Bell de telefoon aan het grote publiek en deze vinding geeft de verbeelding van velen vleugels. Wanneer het mogelijk was het stemgeluid over grote afstand elektrisch te verzenden, dan zou de uitvinding van een soort beeldtelefoon slechts een kwestie van tijd zijn. Deze fantasie wordt extra gevoed door de telefoontechniek te combineren met een andere invloedrijke vinding: de stereoscoop (I838). Tijdens de Londense wereldtentoonstelling van I85I maken de bezoekers voor het eerst kennis met stereofoto's; ze reageren enthousiast. De stereoscoop wordt er niet geëtaleerd als een nieuwe manier om foto's of schilderijen te tonen; uitgangs- 
punt is dat de representatie de realiteit zo dicht mogelijk benadert. Er ontbreekt aan deze 'personen-in-relief' nog slechts één element om ze tot leven te wekken: beweging. ${ }^{25}$

Door de vinding van de telefoon te combineren met de reeds bekende stereoscoop verandert de fantastische voorstelling van het zien over grote afstand voor altijd. Televisie lijkt vóór de uitvinding van de telefoon geen plek te hebben in de collectieve fantasie, simpelweg omdat het idee van een gelijktijdig zintuiglijk 'aanwezig' zijn via technische middelen vóór I 876 onvoorstelbaar was. Dit wordt duidelijk wanneer je literaire teksten over ver-zien van vóór I 876 vergelijkt met die van erna.

Om teksten te onderzoeken op de aanwezigheid van het televisieconcept is het belangrijk het begrip duidelijk af te bakenen. Hiervoor combineer ik John Fiskes omschrijving van een televisie met de ideeën van Lev Manovich over beeldschermen.

Fiske ziet de televisie als een medium dat de toeschouwer een direct beeld geeft van de werkelijkheid; 'it presents

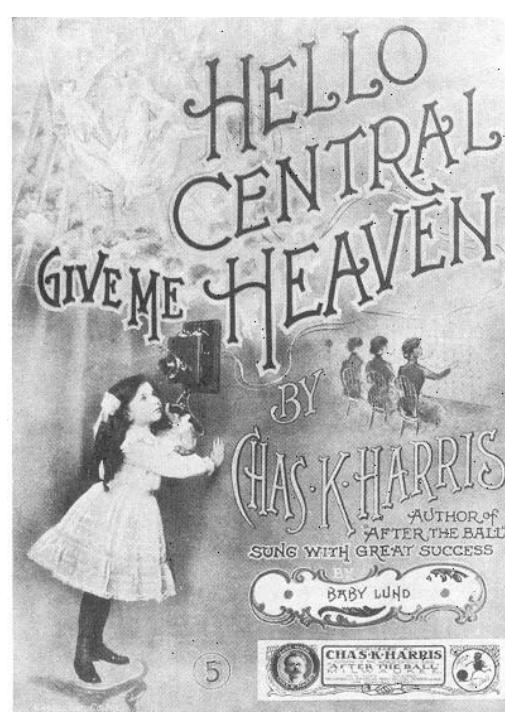

De introductie van de telefoon prikkelt de fantasie. Bron: J. Brooks, Telephone. The First Hundred Years. New York/Londen, Harper \& Row 1976, na p. 82 itself as an unmediated picture of external reality'. In zijn verbeelding staat transparantie centraal; een venster op de wereld. Een glasplaat fungeert als scheiding waardoor de reproductie een onpersoonlijk, objectief, non-cultureel karakter krijgt. '[T]his means that the finished representation is naturalized, that it is made to appear the result of natural rather than cultural processes, it is taken away from the realm of history and culture and moved towards that of universal truth. ${ }^{26}$

Lev Manovich voegt aan Fiskes beschrijving van het medium een beeldschermdefinitie toe. Voor Manovich is een beeldscherm een plat vlak dat aan de voorzijde kan worden bekeken. Het is als een raam naar een andere wereld aanwezig in de ruimte waarin we ons lijfelijk bevinden; 'the existence of another virtual space, another three-dimensional world enclosed by a frame and situated inside our normal space'. ${ }^{27}$ Het frame of de omlijsting scheidt twee totaal verschillende werelden: de virtuele en de alledaagse wereld. Opvallend daarbij is dat het beeld niet dezelfde schaal heeft als de werkelijkheid waarin het wordt getoond. Manovich onderscheidt vier soorten schermen: het klassieke scherm dat een statisch, vaststaand beeld toont (schilderij, foto); het dynamische scherm dat bewegende beelden uit het verleden laat zien (film, televisie, video), het directe scherm dat live beelden weergeeft (computer, live televisie); en het interactieve scherm dat interactie tussen gebruiker en computer mogelijk maakt. ${ }^{28}$

Het directe scherm is interessant voor het oorspronkelijke idee van het concept televisie, omdat daarbij gelijktijdigheid een invulling krijgt. Mensen kunnen live getuige zijn van een gebeurtenis. 
Televisie als raam naar een virtuele werkelijkheid: via een beeldscherm kan de kijker rechtstreeks getuige zijn van een gebeurtenis die gelijktijdig elders plaatsheeft. Bron: A. Smith, Television. An International History. Oxford/New York, Oxford University Press 1995, p. 44

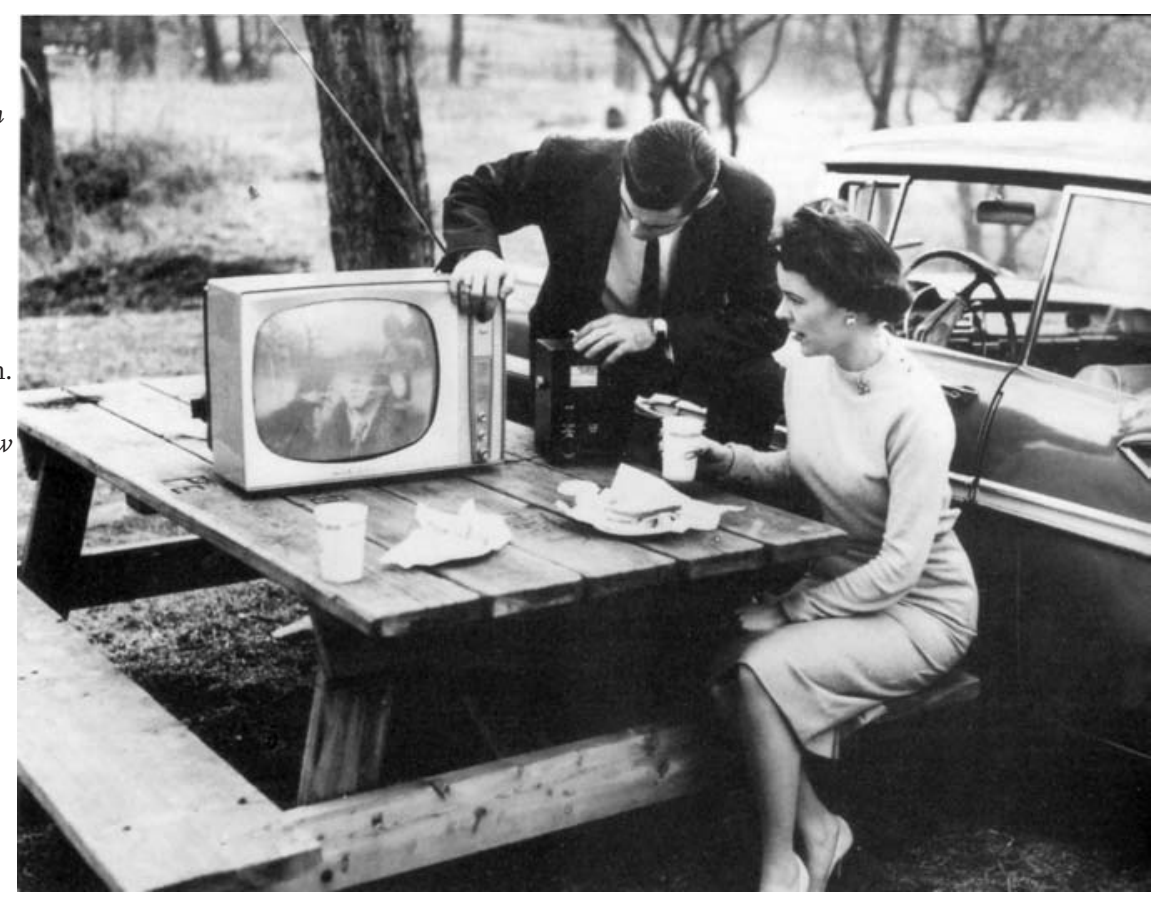

In dit literatuuronderzoek definieer ik het televisieapparaat als een concept dat het mogelijk maakt via een plat beeldscherm rechtstreeks getuige te zijn van een gebeurtenis die gelijktijdig plaats heeft op een andere plaats zonder dat de toeschouwer daarbij zelf aanwezig is. Een glasplaat vormt de scheidslijn tussen beide werelden, waarbij het virtuele beeld niet dezelfde schaal heeft als de werkelijkheid.

\section{Utopieën over televisie}

'This fact also implies that the history of the audiovisual apparatus does not start with its first realisations, but with its utopian and technological drafts', schrijft Jürgen Müller in zijn essay 'Visions of a New History of Television - or Perspectives of a Network History of Television and of Audiovisual Media'. ${ }^{29}$ Müller benadrukt dat voor een geschiedenis van televisie niet alleen de vindingen waaruit deze is voortgekomen interessant zijn, maar ook de fantasieën die over het medium bestonden in een bepaalde periode.

Mijn stelling is dat er binnen de literaire fictie aan het eind van de negentiende eeuw sprake is van een kentering in kijkervaring; schrijvers lijken zich dan pas serieus de technische mogelijkheden voor te kunnen stellen van het gelijktijdig zien op een plaats waar de toeschouwer zich niet bevindt. Het concept van de televisie, zo stel ik, sijpelt pas na de uitvinding van de telefoon in 
I876 langzaam door in de fantastische literatuur. In mijn onderzoek heb ik me beperkt tot twee destijds populaire genres: sprookjes en sciencefiction verhalen. ${ }^{30}$ Volkssprookjes verzameld door de gebroeders Grimm (I8I2-I8I4), cultuursprookjes geschreven door Hans Christian Andersen (I835-I874) en Oscar Wilde (I888); sciencefiction verhalen van Walter Scott [My Aunt Margaret's Mirror (I828)], Jules Verne [Vingt mille lieues sous les mers (I870) en Le chateau des Carpathes (1892)], Albert Robida [Le vingtième siècle (1883)], Camille Flammarion [La fin du monde (I894)] en Herbert G. Wells [When the Sleeper Wakes (I899)]. Deze teksten die in de negentiende eeuw voor het eerst op papier zijn gezet, heb ik getoetst op de aanwezigheid van producten die refereren aan het concept televisie en die voldoen aan de beschrijvingen van John Fiske en Lev Manovich. ${ }^{32}$

Sprookjes spelen zich af in een magische onbepaalde wereld, waarin geen breuk bestaat tussen de mens en fantasiefiguren. In de verhalen gebeuren dingen die onmogelijk zijn. Vooral dit laatste kenmerk maakt het interessant sprookjes te onderzoeken. Hoe omschrijven schrijvers uit de negentiende eeuw dat wat onmogelijk lijkt: het onbelichaamde waarnemen.

In de oudste door mij onderzochte sprookjes, die van de gebroeders Grimm (gepubliceerd tussen I8I2 en I8I4), ${ }^{33}$ is weinig aandacht voor het zien op afstand en wanneer de broers dit thema sporadisch toch behandelen dan maken ze slechts gebruik van een belichaamde wijze van kijken. In Sneeuwwitje voeren ze een jaloerse stiefmoeder op die via een spiegel informatie krijgt over de verblijfplaats van haar mooie stiefdochter; maar de spiegel verschaft haar geen directe verbinding met het kabouterhuis, waardoor ze Sneeuwwitjes handelen rechtstreeks zou kunnen volgen. De broers Grimm voeren in de spiegel een levend orakel op dat de stiefmoeder informeert. 'Koningin, wel schoon zijt gij! Maar Sneeuwwitje, bij de dwergen, ginds daar, over al die bergen, Schooner - duizendmaal - is zij! ${ }^{34}$ Een ander sprookje, Roland, vertelt het verhaal van een heks die twee dochters heeft: een eigen dochter, 'die zeer lelijk en lastig van humeur was, had ze innig lief', en een stiefdochter, 'een even schoon als goedaardig kind, haatte zij onuitsprekelijk'. ${ }^{35}$ Wanneer de heks door een slimme wisseltruc van de stiefdochter haar eigen dochter vermoordt, ontsteekt ze in woede. De gebroeders Grimm schrijven: 'Schuimbekkend van woede liep de heks naar het venster, en wijl haar blik door geen afstand beperkt werd zag zij in de verte haar stiefdochter aan de hand van haren minnaar driftig voortstappen ${ }^{36}$ De waarneming van de heks is dus belichaamd; ze kijkt door het raam naar buiten en ziet haar stiefdochter, omdat ze beschikt over een zeer ontwikkelde blik. Het enige dat in dit sprookje aan de televisie refereert, is dus het venster op de wereld. In De zeeslak fungeren ramen ook als venster op de wereld. Het vertelt het verhaal van een prinses die een kasteel bewoont waar zij ook de beschikking heeft over een torenzaal met twaalf ramen. Vanuit die ramen kan ze het hele rijk overzien. 
'Door het eerste raam zag zij reeds veel scherper dan alle andere menschen, en bij elk raam werd het gezigtsvermogen sterker, zoodat zij bij het twaalfde alles kon nagaan wat op en onder de aarde voorviel, en er niets hoegenaamd voor haar verborgen bleef. ${ }^{37}$ Ramen die het zicht versterken en de prinses een betere blik gunnen op haar omgeving. Een soort van televisie waarbij de kijker zich kan verplaatsen van raam naar raam om een beter beeld te krijgen, maar het kijken blijft gekoppeld aan een lichamelijke aanwezigheid.

Ook Hans Christian Andersen beschrijft in zijn sprookjes (gepubliceerd tussen I835 en I874) geen televisiescherm dat de kijker direct zicht gunt op gebeurtenissen die op hetzelfde moment elders plaatshebben. Alleen de bril uit zijn sprookjesgedicht Grootmoeders bril (I845) doet vaag denken aan een televisie. In het gedicht presenteert Andersen een grootmoeder die door haar bril meer ziet dan enkel haar directe omgeving. 'Zij weet, wat er gebeurt en overal; zij weet ook, wat er 't volgend jaar gebeuren zal'. ${ }^{38}$ Er is dus een glazen afscheiding tussen de wereld van de hoofdpersoon en haar omgeving. Verder ziet ze wat er zich op een andere plaats afspeelt. Maar Andersen beschrijft grootmoeders bril toch vooral als een tovertruc of een paranormale wijze van informatieoverdracht, waarbij het in de toekomst kunnen zien centraal staat. Wanneer zij haar bril uitleent aan haar kleinzoon zegt deze:'Mijn eigen toekomst? Ja de eigen vreugd en smart. (...) Ik zie 't maar ' $\mathrm{k}$ kan 't niet zeggen, wat ik aanschouw, als het gebeurt, dan hoort gij het al gauw.'39

In De visser en zijn ziel (I888) beschrijft Oscar Wilde het concept televisie op subtiele wijze zonder de typische sprookjeswereld geweld aan te doen. Een visser wordt verliefd op een zeemeermin, die zijn liefde echter niet kan beantwoorden zolang hij nog een mensenziel heeft. 'Als ge alleen uw ziel maar wilde wegsturen, dan zou ik van u kunnen houden', zegt de zeemeermin. De visser gaat op zoek naar een heks die hem van zijn ziel kan verlossen. Deze vrouw, die zich ook aangetrokken voelt tot de visser, eist als tegenprestatie voor het verwijderen van zijn ziel dat hij met haar danst op de top van de berg. De visser gaat hiermee akkoord en vertrekt.

'En de heks sloeg hem gade toen hij wegging, en toen hij uit het gezicht was verdwenen ging zij haar grot binnen, en nadat zij een spiegel uit een kistje van uitgesneden cederhout had genomen, zette zij hem op een draagraam en brandde er verbena op gloeiende houtskool voor, en tuurde door de rookslierten. En na enige tijd sloeg zij de handen boos ineen. "Hij had de mijne behoren te zijn," mompelde zij. "Ik ben even mooi als zij is". 40

Televisie als een magisch ritueel voor een spiegelende glasplaat. Wilde laat het aan de fantasie van de lezer over wat de heks precies ziet, maar het is wel duidelijk dat de visser na zijn bezoek terugkeert naar zijn geliefde. De heks ontvangt livebeelden van hun ontmoetingsplek en kan hierdoor haar eigen schoonheid vergelijken met die van de zeemeermin. 
In de door mij onderzochte sprookjes uit de negentiende eeuw zitten geen duidelijke aanknopingspunten met de techniek van het televisietoestel. Oscar Wildes sprookje uit I888, dat geschreven is nadat de telefoontechniek is gepresenteerd aan het publiek, refereert nog het meest aan het concept, maar blijft toch te doordesemd van de magische sprookjessfeer: rituelen, rookslierten en spiegelingen om te zien wat eigenlijk niet te zien is. Sprookjes spelen zich dan ook meestal af in een niet-technologisch wereld, waar natuurverschijnselen en toverkracht de boventoon voeren. Het is in dit verband overigens interessant om het sprookje The Wonderful Wizard of Oz van Lyman Frank Baum uit I9oo te vergelijken met de verfilming van het sprookje in I939. Terwijl in het boek de Boze Heks van het Westen met het blote oog over grote afstand kan zien, heeft de heks in de film THE WIZARD of Oz (USA: Victor Fleming, I939) een glazen bol tot haar beschikking waarin ze rechtstreeks de reis van Dorothy en haar reisgezellen naar Oz kan volgen. De film is dan ook een product van de jaren dertig, een periode waarin druk met televisie in de publieke sfeer werd geëxperimenteerd. ${ }^{4 \mathrm{I}}$ Een heks die in een glazen bol kijkt naar wat zich elders afspeelt, is dus een combinatie van de sprookjesmagie en de mediale innovaties uit die periode - iets waarvan in het boek nog geen sprake is:

'Nu had de Boze Heks van het Westen maar één oog. Maar dat oog was sterker dan de sterkste verrekijker en dat kon alles zien, wie of wat er aan kwam. Toen ze dus midden in de poort van het kasteel zat en zo maar met haar ene oog rondkeek, zag ze Doortje [Dorothy] liggen slapen, met al haar vrienden om haar heen. ${ }^{42}$

\section{De sciencefiction verhalen}

Sciencefiction vertellingen spelen zich af in een denkbeeldige wereld, meestal in de toekomst, waarin de techniek een grote vlucht heeft genomen. Kenmerkend binnen dit genre zijn de verzonnen wetenschappelijke uitvindingen die het onmogelijk geachte mogelijk maken. Schrijvers binnen dit genre maken vaak op extrapolerende wijze gebruik van actuele wetenschappelijke gegevens. ${ }^{43}$ Daarom is het interessant op welke wijze zij het concept televisie benaderen.

My Aunt Margaret's mirror (I828) ${ }^{44}$ van Walter Scott is eigenlijk meer een fantastische vertelling dan een sciencefiction. Ik wil het verhaal toch kort bespreken, omdat Scott een bijzondere constructie opvoert waarmee de illusie wordt gewekt dat het mogelijk is op afstand te zien zonder daadwerkelijk aanwezig te zijn. Een tante vertelt haar neef

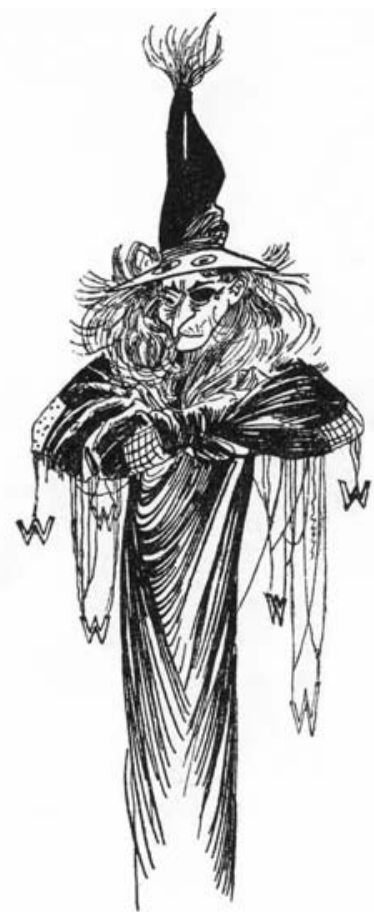

De heks had maar één oog, maar dat was sterker dan de sterkste verrekijker. Bron: L.F. Baum, De grote tovenaar van Oz. Amsterdam, Veen's Uitg. Mij. 1940, p. 109 
het verhaal van een vrouw die op zoek is naar haar verdwenen echtgenoot. De vrouw besluit een rondreizende dokter uit Padua te raadplegen over wie wordt verteld dat hij weet wat het lot is van hen die afwezig zijn. Tijdens het consult leidt de dokter de vrouw naar een grote ruimte. De schaarse verlichting en de zwarte bekleding van de muren creëren een lugubere begrafenissfeer, die nog wordt versterkt door het centraal staande altaar waarop allerlei objecten liggen, zoals een mensenschedel, twee kruislings liggende zwaarden en een opengeslagen bijbel. Achter het altaar staat een gigantische spiegel. Wanneer de vrouw heeft plaatsgenomen voor het altaar, treden er veranderingen op in het spiegelbeeld. ${ }^{45}$ Geleidelijk verschijnt het beeld van een kerk waarin een huwelijksplechtigheid plaatsheeft tussen de verdwenen echtgenoot en een andere vrouw. Scott laat de lezer in dubio over het waarheidsgehalte van de beschreven beelden. De dokter geeft aan dat ze of gelijktijdig plaatsvinden, of dat ze kort ervoor hebben plaatsgehad. Maar de tante die het verhaal vertelt en het weer heeft gehoord van haar grootmoeder, trekt diens verklaring in twijfel. Zij weet dat het huwelijk enkele dagen eerder werd voltrokken. Haar neef concludeert dan dat de dokter hiervan op de hoogte moet zijn geweest en dat hij de beeldenreeks zelf in scène heeft gezet. Scott laat zich duidelijk inspireren door de in zijn tijd populaire fantasmagorievoorstellingen. ${ }^{46}$ Zijn uiteindelijke verklaring van het tafereel in de spiegel wijst meer in de richting van het magisch theatrale dan van virtuele beelden van wat zich gelijktijdig elders afspeelt.

Jules Verne wordt vaak gezien als de grondlegger van de sciencefiction. In 20.000 mijlen onder zee (I870) beschrijft hij een futuristisch onderwaterschip waarin het mogelijk is van achter glas het leven onder de zeespiegel te observeren. Verne schrijft: 'Plotseling werd het dag aan weerszijden van de zaal door twee ovale openingen; het zeewater was helder verlicht door een electriek licht. Twee dikke glasschijven scheidden ons van de zee.' Door het glas is het mogelijk te zien wat er op grote diepte onder water gebeurt; dit voldeed aan de droom te zien op plaatsen waar dat destijds nog niet mogelijk was. Het hoofdpersonage is via een raam getuige van een zinderend schouwspel ver onder de zeespiegel; hij verzucht: 'Nooit was mij het geluk te beurt gevallen, die dieren levend en vrij in hun natuurlijke element te aanschouwen. ${ }^{47}$ Het beeldscherm dat Verne beschrijft vormt een glazen scheiding tussen de wereld van de kijker en de wereld die deze observeert, maar de verbinding tussen oog en lichaam blijft gehandhaafd. Het beeldscherm is letterlijk een venster op de wereld, waarbij ook het schaalniveau van de werkelijke en virtuele wereld gelijk blijft.

Pas in zijn roman Het kasteel in de Karpaten (I892), zestien jaar na de 'uitvinding' van de telefoon, fantaseert Verne voor het eerst over het concept televisie. Hij beschrijft het verhaal van een baron die een groot bewonderaar is van de operazangeres Stilla. Wanneer deze zangeres besluit te stoppen, houdt hij op een bijzondere wijze de herinnering aan haar levend. Hij laat zijn knecht haar laatste concert opnemen, trekt zich terug uit de wereld in een afgelegen kasteel, en 


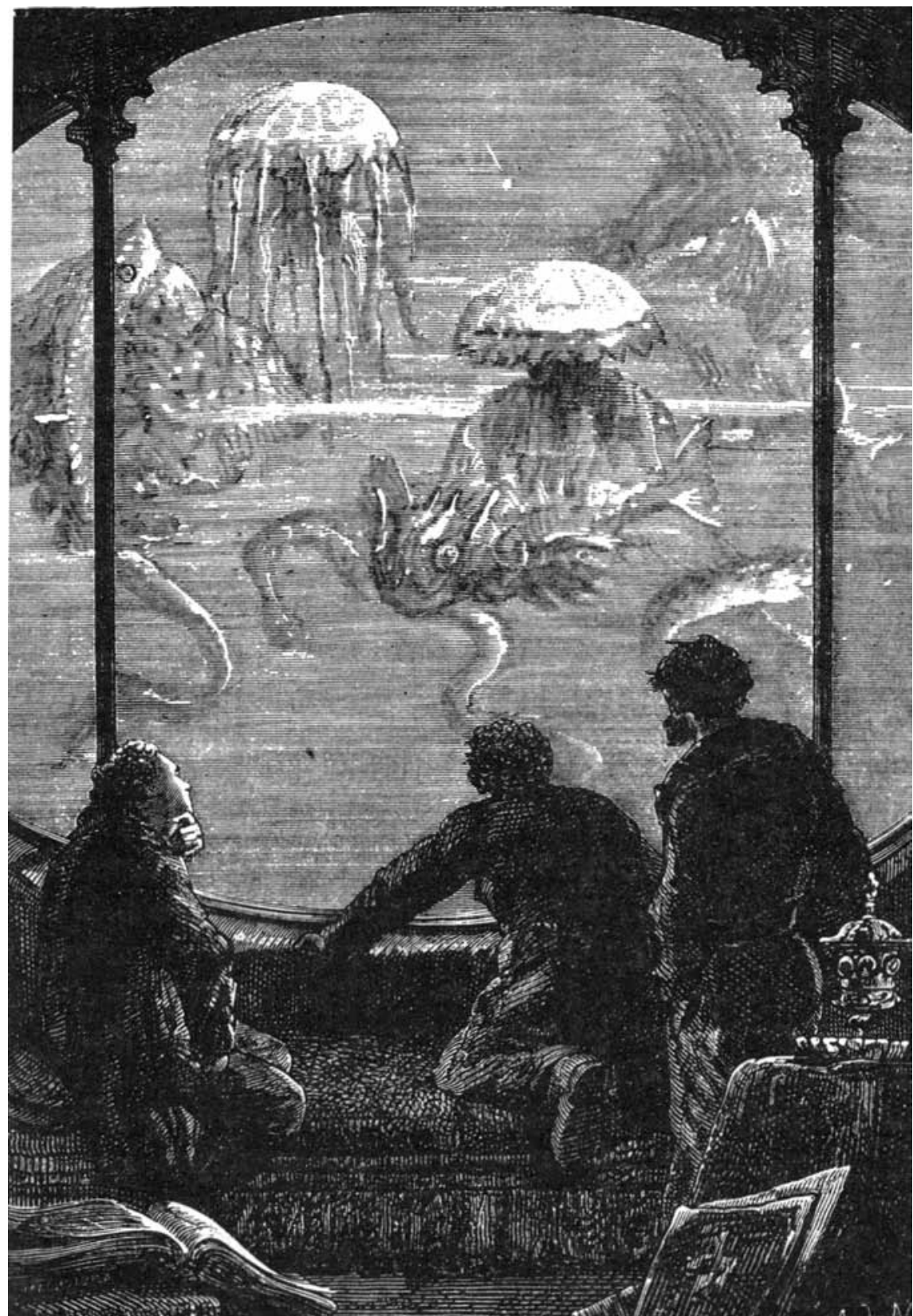

Door glas het leven onder de zeespiegel bestuderen.

Illustratie: De Neuville.

Bron: J. Verne.

Vingt mille lieus sous les mers. Parijs, Bibliothéque d'Education et de Récréation 1990, p. 147

speelt in de avonduren de opgenomen muziek af. Daarbij projecteert hij als een soort fantasmagorie via bolle spiegels een levensgroot schilderij op een glazen plaat. Zo creëert hij geen televisie, maar wel een soort monitor waarop een DVD wordt afgespeeld. Verne verwijst in zijn boek naar de technische innovaties aan het eind van de negentiende eeuw: van alle elektrische toestellen 'werkte de tele- 
Via de telefonoscoop thuis colleges volgen. Illustratie: Albert Robida.

Bron: 'Albert Robida 1848-1926.' Cahier de l'art mineur, nr. 8 (1976)

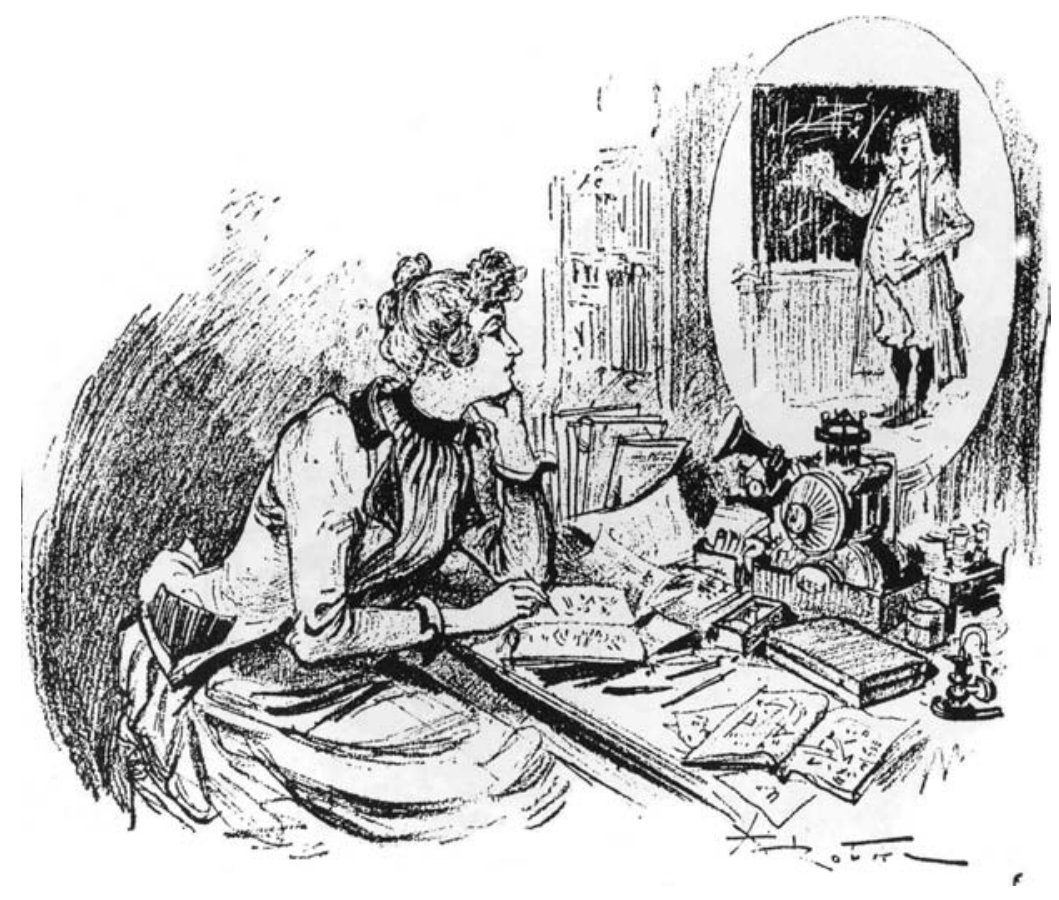

foon met eene zoo wonderbare nauwkeurigheid, dat men niet eens meer een hoorn noodig had om de klanken op te vangen, die tegen de plaatjes aandruischten. Alles wat gezegd, gezongen, zelfs gemompeld werd, kon men verstaan, op welke afstand ook, en twee personen door duizenden mijlen gescheiden, spraken met elkander, alsof zij naast elkaar zaten' ${ }^{48}$

Vernes landgenoot Albert Robida wordt vaak genoemd als de eerste auteur die een apparaat beschrijft dat lijkt op de televisie. In zijn roman Le vingtième siècle $(\mathrm{I} 883)^{49}$ creëert hij een beeld van de Parijse samenleving in I952/1953 met daarin fantastische nieuwe uitvindingen zoals luchttaxi's, transport via buizen en ruimteschepen. Een voor mijn onderzoek interessant object is de telefonoscoop, waarmee het mogelijk is over afstand te zien en te horen. Via een normale telefoonverbinding kunnen dialogen en muziek worden beluisterd, waarbij ook de mogelijkheid bestaat livebeelden te bekijken op een glazen plaat. Kijkers zijn zo thuis getuige van onbeschrijfelijke gebeurtenissen. Zij kunnen rechtstreeks oorlogshandelingen volgen, waarbij een verslaggever live het commentaar geeft. ${ }^{50}$ Het apparaat bestaat uit een glazen plaat in een kast, waar de toeschouwer voor gaat zitten en een programma kiest. De beschrijving van Robida voldoet hiermee dus helemaal aan de definiëring van John Fiske en Lev Manovich. In Robida's fantasie is het medium nog wel gebonden aan bekabeling (kabeltelevisie), want dat signalen ooit draadloos uit de ether zouden worden geplukt, was voor hem nog ondenkbaar. ${ }^{\text {.T }}$ 


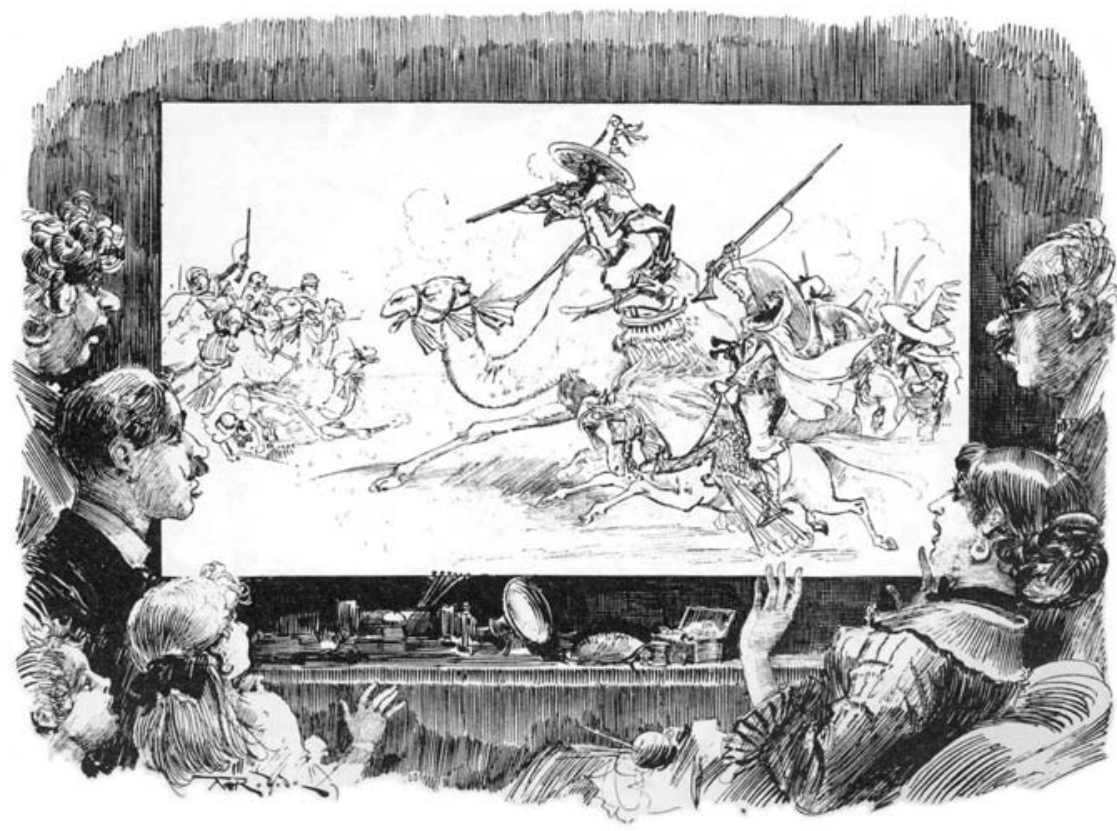

In de roman Het vergaan der wereld (I894) beschrijft Camille Flammarion de samenleving van de dertigste eeuw. Hij staat uitgebreid stil bij een toestel dat sterk doet denken aan de televisie. Een telefoon biedt de wereldbevolking de mogelijkheid contact met elkaar te zoeken en met de telefonoscoop 'kon men de meest merkwaardige of meest belangrijke gebeurtenissen op de geheele aarde zien.' Of het nou om een toneelvoorstelling in Chicago gaat of een bijzondere ontmoeting elders, op elke plaats in de wereld kunnen mensen dit vanuit het eigen huis meebeleven. Via een knoppensysteem kan de gebruiker zappen. Een stroomwisselaar legt onmiddellijk verbinding met iedere plaats op aarde. Flammarion borduurt voort op de ideeën van Robida in Le vingtième siècle. Zijn fantasie gaat echter verder. In Het vergaan der wereld heeft de mens door training van de hersenwerking de zintuiglijke perceptie over afstand verruimd. Taferelen op een andere locatie zijn niet alleen te zien en te horen, maar ook te voelen en aan te raken. ${ }^{52}$ Flammarion zet de deur open voor een volmaakte virtuele ervaring.

Tot slot de toekomstvertelling When the Sleeper Wakes (I899) ${ }^{53}$ van Herbert G. Wells. In dit verhaal slaapt een man uit de negentiende eeuw ruim tweehonderd jaar. Hij ontwaakt in een volledig veranderde wereld. Op een bijna kinderlijke wijze kijkt de man om zich heen en ziet de meest ongelofelijke technische mogelijkheden. Zo beschrijft Wells ook een televisietoestel, een ovaal scherm dat wanneer het wordt aangezet beelden in kleur toont van een revolutie die elders in de stad plaatsheeft. ${ }^{54}$
Via de telefonoscoop thuis de oorlog live volgen. Illustratie: Albert Robida. Bron: Albert Robida, Luftschlösser der Belle Époque. Die besten utopischen Bilder aus "Le Vingtième Siècle" (1883). Dortmund, Harenberg Kommunikation 1979, p. 85 
Omdat sciencefiction schrijvers in hun toekomstfantasieën voortborduren op de hen omringende werkelijkheid, vertalen zij ideologische idealen en technische ontwikkelingen die in een maatschappij leven naar een andere tijd of omgeving. Zij extrapoleren dat wat ze kennen of weten tot een virtuele omgeving die past in hun futuristische verhalen. Dat maakt het zo boeiend om sciencefictions te analyseren op sporen die naar onze tijd leiden. Net als bij de sprookjes heb ik in de negentiende-eeuwse sciencefiction literatuur vóór de jaren tachtig geen voorbeelden gevonden waarin schrijvers het televisieconcept op een serieuze manier behandelen zonder daarbij gebruik te maken van magische of theatrale elementen. Walter Scott lijkt het concept te beschrijven; maar wanneer hij het verschijnsel verklaart, blijkt er geen beeldtransmissie plaats te vinden en zijn de beelden in de spiegel een onderdeel van een fantasmagorievoorstelling. Zijn tijdgenoot Edgar Allan Poe laat zich in zijn fantastische vertellingen ook leiden door deze destijds populaire vorm van volksvermaak; hij schrijft over magische geestverschijningen en bovennatuurlijke gebeurtenissen, maar niets dat de televisie beschrijft. Pas aan het eind van de negentiende eeuw gaan schrijvers als Jules Verne, Albert Robida, Camille Flammarion en Herbert G. Wells serieus in op het concept van het onbelichaamd zien wat er elders op hetzelfde moment gebeurt. De techniek had zich in die periode zover ontwikkeld dat schrijvers zich een voorstelling konden maken van dit televisieprocédé. En zoals Jonathan Crary binnen de visuele cultuur aangeeft dat de waarneming plaatsheeft binnen de kaders van het bevattingsvermogen, zou je binnen de literatuur lezers kunnen zien als imaginaire toeschouwers die de geloofwaardigheid van verhalen toetsen aan dat wat zij mogelijk achten. Het voorstellingsvermogen is de leidraad van schrijver en lezer. Voor de vinding van de telefoon kon men zich niet voorstellen een gebeurtenis rechtstreeks waar te nemen zonder er lijfelijk bij aanwezig te zijn.

\section{Conclusie}

In dit essay betoog ik dat pas na de uitvinding van de telefoon in 1876 en de technische innovaties die hierop volgen schrijvers zich een voorstelling kunnen maken van de mogelijkheden die een onbelichaamd waarnemen heeft. Pas vanaf dit moment maken ze in hun verhalen gewag van een apparaat dat doet denken aan de televisie; het zijn dan nog utopieën, want John L. Baird presenteert dit medium pas in 1925 aan het publiek. Het oog dat op een andere plek dingen ziet die gelijktijdig plaatshebben zonder dat de kijker zich daar ook lichamelijk bevindt, past in het idee van Jonathan Crary dat de toeschouwer verandert onder invloed van optische innovaties. Crary stelt dat de mens aan het begin van de negentiende eeuw een nieuwe wijze van kijken ontwikkelt; de belichaamde blik transformeert in een ontworteld zien, waarbij de ogen binnen de waarneming centraal komen te staan; de rest van het lichaam doet niet meer mee. 


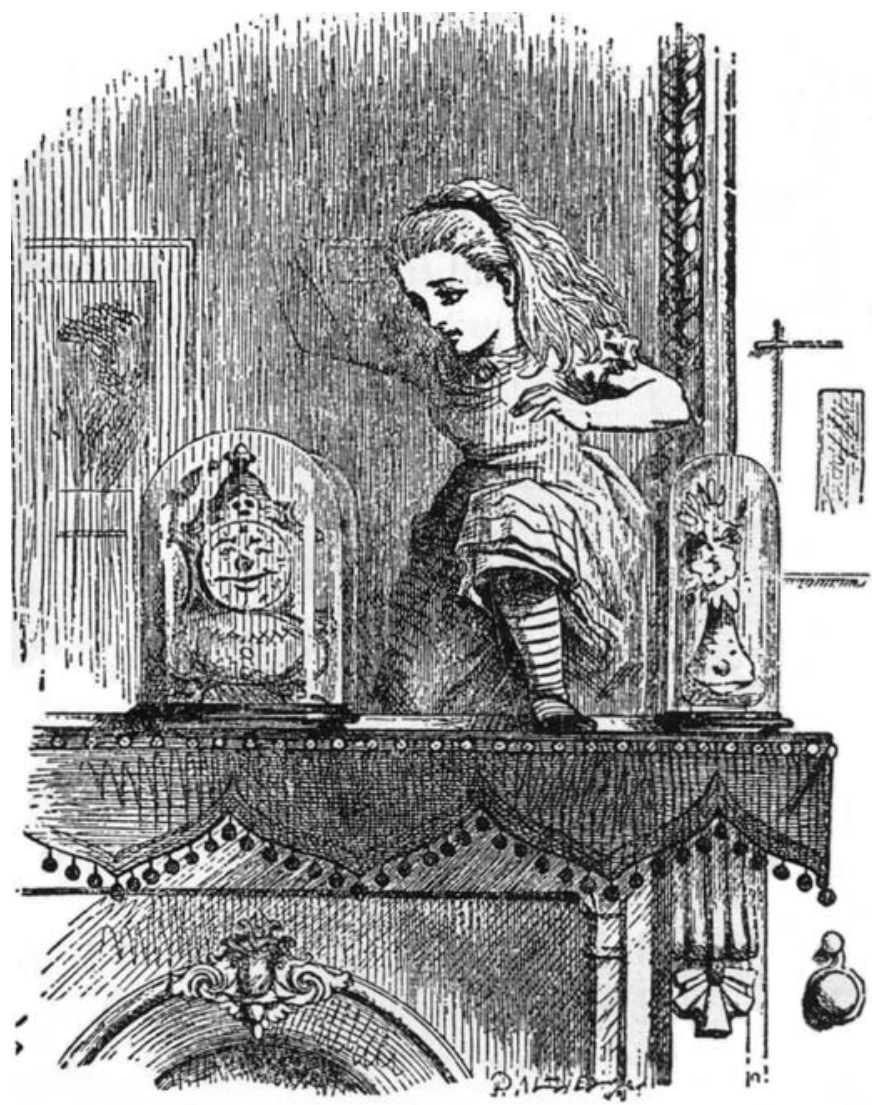

Het is niet mijn bedoeling de ideeën van Crary ter discussie te stellen. Hij beroept zich op de visuele cultuur van de negentiende eeuw. Uitgaande van de populaire cultuur betoog ik dat zijn periodisering geen onderbouwing vindt in de negentiende-eeuwse literatuur. Natuurlijk is dit onderzoek niet grootschalig genoeg om aan de resultaten verstrekkende conclusies te verbinden. Het zou interessant zijn het waarheidsgehalte van mijn bevindingen diepgravender te bestuderen. Mogelijk blijkt uit zo'n onderzoek dat schrijvers uit de negentiende eeuw zich gewoonweg niet konden voorstellen, dat mensen ooit avond aan avond via een 'kijkglas' verbinding zouden zoeken met een werkelijkheid elders. Misschien leek het hen veel aantrekkelijker net als Alice gewoon zelf lichamelijk in een virtuele wonderwereld aanwezig te zijn.

"Oh, Kitty, how nice it would be if we could only get through into Lookingglass House! I'm sure it's got, oh! such beautiful things in it! Let's pretend there's a way of getting through into it, somehow, Kitty. Let's pretend the glass has got all soft like gauze, so that we can get through. Why, it's turning into a sort of mist now, I declare! It'll be easy enough to get through". ${ }^{5}$
'En het glas begon nu echt weg te smelten, alsof het een licht zilveren waas was. Even later was Alice het glas door en was ze met een luchtige sprong in de Spiegelkamer beland.' Illustratie: John Tenniel. Bron: L. Carroll, De avonturen van Alice in Wonderland \& Achter de spiegel. Vert. Nicolaas Matsier. Amsterdam, Van Goor 1994, p. 139-141 


\section{Noten}

I L. Carroll, The Complete Works of Lewis Carroll, Londen I939, p. I33.

2 'Looking-glass house' is een mooie vondst van Lewis Carroll. In het Engels zijn er twee woorden voor spiegel: naast looking-glass ook mirror. Met looking-glass accentueert hij het venster waardoor Alice naar een andere, gespiegelde wereld kijkt. In de Nederlandse vertaling kiest Nicolaas Matsier voor 'spiegelhuis'. Deze term prikkelt de fantasie minder omdat het idee van een andere wereld achter glas verloren gaat. (L. Carroll, De avonturen van Alice in Wonderland Q Achter de spiegel. Vertaling Nicolaas Matsier. Amsterdam I994, p. 139).

3 J. Crary, Techniques of the Observer. On Vision and Modernity in the Nineteenth Century, Londen I990, p. 3-7.

4 S. Neale, Cinema and Technology. Image, Sound, Colour, Londen I985, p. 54-55. Steve Neale citeert Le magasin pittoresque (maart 1895 ).

5 G. Sadoul, Louis Lumière, Paris I964, p. II7-I20.

6 In 1925 slaagt de Schotse uitvinder John L. Baird erin om voor het eerst een televisiebeeld draadloos over te brengen. (A. Abramson, The History of Television, 1880 to 1941, Londen 1987, p. $73-83)$.

7 Charles Wheatstone en David Brewster gelden als de uitvinders van de stereoscoop. Het is een optisch toestel voor het bekijken van stereoscopische beelden, zodat deze diepte krijgen en daarmee echter lijken. 'Its "realism" presupposes perceptual experience to be essentially an apprehension of differences. The relation of the observer to the object is not one of identity but an experience of disjunct or divergent images.' (Crary, Techniques of the Observer, p. I20).

8 De phenakisticoop is een uitvinding van de Belgische geleerde Joseph Plateau. Uit de omtrek van een schijf zijn vlakjes weggesneden. Op een andere draaischijf staan op de omtrek tekeningetjes die de opeenvolgende fasen van een beweging verbeelden. Wanneer de schijf draaiend voor een spiegel wordt gehouden, is een dansend figuurtje te zien of een springend paardje, al naar gelang van de aangebrachte tekening. (E. Brumsteede, Film, Amsterdam I958, p. I4).

9 Abramson, History of Television, p. 2-4.

Io W. Uricchio, 'Cinema als omweg? Een nieuwe kijk op de geschiedenis van het bewegende beeld', Skrien, nr. 199 (1994-1995), p. 54-56.

II Een uitvinding is geen geïsoleerde gebeurtenis. Het patenteren en presenteren van een vinding is slechts een momentopname in een doorlopend proces, waarin ideeën leiden tot prototypes die worden vervolmaakt, eventueel in de markt worden gezet en vaak weer leiden tot andere innovaties. (zie: B. Winston, Media Technology and Society. A History: From the Telegraph to the Internet, Londen 2003, p. I-I5; B. Winston. Misunderstanding Media, Londen I986, p. I7-23). Brian Winston beschrijft dit proces in Media Technology and Society en Misunderstanding Media onder andere voor de 'uitvinding' van de telefoon (resp. p. 30-60, en p. 293-362).

I2 Zie ook: M. Elsner, Th. Müller \& P. Spangenberg, 'Der lange Weg eines schnellen Mediums: Zur Frühgeschichte des deutschen Fernsehens', in: W. Uricchio (red.), Die Anfänge des Deutschen Fernsehens. Kritische Annäherungen an die Entwicklung bis 1945, Tübingen I99I, p. I53-207.

I3 J.E. Müller, Intermedialität. Formen moderner kultureller Kommunikation, Münster I996, p. 57-58.

I4 Th. Elsaesser, 'Early Film History and Multi-Media: an Archaeology of Possible Futures?', in: W. Chung (ed.), The Archaeology of Multimedia, New York, ter perse. Zie ook: Th. Elsaesser en K. Hoffmann (eds), Cinema Futures: Cain, Abel or Cable? The Screen Arts in the Digital Age, Amsterdam I998, p. 47-5I.

I5 K. Hickethier, Geschichte des deutschen Fernsehens, Stuttgart I998, p. 8.

I6 Abramson, History of Television, p. 2.

I7 Abramson, History of Television, p. 3. Siegfried Zielinski benadrukt in Audiovisions dat film en televisie, ondanks de ogenschijnlijke overeenkomsten, zich op technisch gebied vooral los van elkaar ontwikkelden. '[T]he two intrinsic targets of the projects were poles apart and seemed to run parallel to one another without direct contact. In contradistinction to the preservation of images for the purpose of processing and presenting them, the lineage of television is concerned essentially 
with overcoming spatial distance without any loss of time (as the tendency).' (S. Zielinski, Audiovisions. Cinema and Television as Entr'actes in History. Vertaling G. Custance. Amsterdam I999, p. 50 ).

I8 Crary, Techniques of the Observer, p. 6.

I9 Crary, Techniques of the Observer, p. 9.

20 Een fantasmagorie is een theatrale voorstelling waarbij door een toverlantaarn en optische effecten spookachtige gedaanten worden gecreëerd. Zie ook: T. Castle. 'Phantasmagoria: Spectral Technology and the Metaphorics of Modern Reverie', Critical Inquiry, herfst I988, p. 26-52; Brumsteede, Film, p. 20-2I.

2I Crary, Techniques of the Observer, p. I38.

22 Crary, Techniques of the Observer, p. I3.

23 R.E. Raspe, De zonderlinge reizen en avonturen van den baron Van Munchhausen. Vertaling niet bekend [Huaheine, bij Omai], I790, p. I88.

24 Raspe, Van Munchhausen, p. I89.

25 Crary, Techniques of the Observer, p. I22; zie ook Brumsteede, Film, p. 22.

26 J. Fiske, Television Culture, Londen I987, p. 2I.

27 L. Manovich, The Language of New Media, Londen 200I, p. 95.

28 Idem, p. 95-I03.

29 J.E. Müller, 'Visions of a New History of Television - or Perspectives of a Network History of Television and of Audiovisual Media', Quaderns de Filologia. Estudis de Comunicació, Vol. I (2002), p. I99.

30 Zie o.a. F.W. Korsten, Lessen in literatuur, Nijmegen 2002, p. I92; R. Ghesquiere, Het verschijnsel jeugdliteratuur, Amersfoort 2000, p. I39.

3I Rita Ghesquiere maakt in Het verschijnsel jeugdliteratuur een onderscheid tussen een logisch opgebouwde fantasiewereld en de logisch indifferente wereld van de nonsensliteratuur. De logisch opgebouwde fantasiewereld verdeelt ze in verhalen die zich afspelen in één homogene wereld (sprookje, sciencefiction et cetera) en verhalen die zich afspelen in twee werelden (sage, legende et cetera). (Ghesquiere, Het verschijnsel jeugdliteratuur, p. I39). Ik kies in dit onderzoek voor verhalen die zich afspelen in één homogene wereld.

32 Het betreft hier een willekeurige lijst teksten, waardoor mijn onderzoek als niet representatief moet worden beschouwd. Uit oogpunt van eenheid heb ik in mijn onderzoek zoveel mogelijk gekozen voor Nederlandse vertalingen; ik ben me ervan bewust dat zo'n vertaling van invloed kan zijn op het uiteindelijk resultaat van dit onderzoek. Wel heb ik telkens gekozen voor de oudst beschikbare vertaling. Daarbij heb ik bij onduidelijkheden (bijvoorbeeld weglatingen of opvallende details in de vertaling) altijd de (meest) originele bron geraadpleegd. Wanneer ik geen Nederlandse vertaling kon vinden, ben ik uitgegaan van de originele tekst.

33 Grimm, Kinder- und Hausmärchen (I8I2-I8I4).

34 Gebr. Grimm, Sprookjes en vertellingen van de gebroeders Grimm. Deel $2[=\mathrm{A}]$. Vertaling A. van der Velde. 's-Gravenhage I878, p. 5 .

35 Idem, p. 35 (A).

36 Idem, p. 36 (A).

37 Gebr. Grimm, Sprookjes en vertellingen van de gebroeders Grimm. Deel $4[=\mathrm{B}]$. Vertaling A. van der Velde. 's-Gravenhage I878, p. 168.

38 H.C. Andersen, Sprookjes. Vertaling Marie W. Vos. Amsterdam I943, p. 66.

39 Andersen, Sprookjes, p. 67.

40 O. Wilde, Sprookjes. Het Sterrekind en andere sprookjes. Vertaling M. Schuchart. Den Haag I980, p. 63-69. Vertaling van Oscar Wildes The Fisherman and his Soul. 'And the Witch watched him as he went, and when he passed from her sight she entered her cave, and having taken a mirror from a box of carved cedarwood, she set it up on a frame, and burned vervain on lighted charcoal before it, and peered through the coils of the smoke. And after a time she clenched her hands in anger. "He should have been mine," she muttered, "I am as fair as she is." (O. Wilde, The works of Oscar Wilde. A house of pomegranates, The Happy Prince, and Other Tales, New York 1909, p. 84).

4I Zielinski, Audiovisions, p. I72-I8I. 
42 L.F. Baum, De grote tovenaar van Oz. Vertaling H. Scholte. Amsterdam I940, p. IO9-IIO.

43 H. Gorp, R. Ghesquiere, D. Delabastita, Lexicon van literaire termen, Groningen I998, p. 398. De website 'Histoire de la television' van André Lange is in dit kader ook interessant. Hij verzamelt hierop tal van artikelen die in de negentiende eeuw werden gepubliceerd over televisie en waardoor schrijvers als Jules Verne, Albert Robida, Camille Flammarion en Herbert G. Wells zich mogelijk lieten inspireren voor hun fantastische toekomstbeelden. (Histoire de la television, 24 december 2004, http://histv2.free.fr).

44 Van deze roman heb ik de originele tekst gebruikt. Een Nederlandse vertaling heb ik niet kunnen vinden.

45 In My Aunt Margaret's Mirror schrijft Scott: 'Suddenly the surface assumed a new and singular appearance. It no longer symply reflected the objects placed before it, but, as if it had self-contained scenery of its own, objects began to appear within it, at first in a disorderly, indistinct, and miscellaneous manner, like form arranging itself out of chaos; at length, in distinct and defined shape and symmetry.' (W. Scott, Chronicles of the Canongate, Parijs I832, p. 2I7).

46 De tante antwoordt de neef: 'It certainly seemed probable that intelligence from the Continent, which could easily have been transmitted by an active and powerful agent, might have enabled him to prepare such a scene of phantasmagoria as she had herself witnessed.' (Scott, Chronicles, p. 222-223). In een artikel over de fantasmagorie stelt Terry Castle dat deze attractie zo'n impact had dat veel schrijvers uit de negentiende eeuw haar opnamen in hun boeken en gedichten als metafoor of als techniek om een bovennatuurlijke werkelijkheid te creëren. (Castle, 'Phantasmagoria', p.43-52).

47 J. Verne, 20.000 mijlen onder zee. Vertaler niet bekend. Leiden I876, p. I00-I05. In De reis naar de maan in 28 dagen en 12 uren (De la terre à la lune - I865) beschrijft Verne een soortgelijke kijkervaring. In de raket die drie mannen naar de maan brengt, zitten ramen die een prachtig uitzicht geven op maan. Verne schrijft: 'Ontzettend schouwspel! Het was als een geweldige uitbarsting van een vulkaan of een onmetelijke brand. Duizend vonken en vuurbrokken van allerlei kleuren vlogen in het rond en van de reusachtige vuurbol bleef niets anders over dan splinters, als sterretjes rondzwevend in de onmetelijke ruimte.' (J. Verne, De reis naar de maan in 28 dagen en 12 uren. Vertaler niet bekend. Amsterdam I974, p. I83).

$48 \mathrm{~J}$. Verne, Het kasteel in de Karpaten. Vertaler niet bekend. Rotterdam zj [I8xx], p. I70. In een voetnoot voegt Verne hieraan toe dat ze elkaar zelfs konden zien via glazen platen die door draden met elkaar verbonden waren. Verne schrijft: 'Elles pouvaient même se voir dans des glaces reliées par des fils, grâce à l'invention du téléphote.' (J. Verne, Le château des Carpathes, Parijs I928, p. I77). Bij de vertaling van Het kasteel in de Karpaten uit het eind van de negentiende eeuw is om onduidelijke reden deze voetnoot van de auteur weggelaten. In een vertaling uit 1983 is de voetnoottekst wel opgenomen: 'Ze konden elkaar zelfs, dankzij de uitvinding van de telefoon met behulp van door draden met elkaar verbonden spiegels, zien!' (J. Verne, Het spookkasteel. Vertaling I. Hölscher. Amsterdam I983, p. I64).

49 Van deze roman heb ik de originele tekst gebruikt. Een Nederlandse vertaling heb ik niet kunnen vinden.

50 Robida schrijft: '(...) communication avec tous les correspondants du journal, aussi bien à Paris même qu'au cœur de l'Océanie. Un événement important se produisait-il, le correspondant, armé d'un petit téléphonoscope de poche, assurait sa communication électrique et braquait son instrument sur le point intéressant; aussitôt, sur le grand téléphonoscope du journal apparaissait, considérablement agrandie, l'image concentrée sur le champ limité du petit téléphonoscope. (A. Robida, Le vingtième siècle. Roman d'une Parisienne d'après-demain, Parijs z.d., p. 207-208). Zie ook: A. Haakman, 'De toekomst van honderd jaar geleden. Film en televisie in I894', Skrien, nr. 199 (I994-I995), p. 53; W. Petri, Lufschlösser, der Belle Époque. Die besten utopischen Bilder aus 'Le Vingtième Siècle' (1883), Dortmund 1979; Histoire de la television, 24 december 2004, http://histv2. free.fr/anthologie.htm.

5I In I896 ziet Guglielmo Marconi voor het eerst kans draadloos over afstand te communiceren; hij is hiermee de uitvinder van de draadloze telefonie.

52 C. Flammarion, Hetvergaan der wereld. Vertaling B.C. Goudsmit. Zutphen I899, p. 258-259. 
53 Van deze roman heb ik de originele tekst gebruikt. Een Nederlandse vertaling heb ik niet kunnen vinden.

54 Wells schrijft: "Then he saw that the cloudy grey disc had taken depth and colour, had assumed the appearance of an oval window looking out upon a strange unfamiliar scene. (...) He judged that this mirror was some modern replacement of the camera obscura, but that matter was not explained to him.'(H.G. Wells, When the Sleeper Wakes, Londen/New York I899, p. I42).

55 Carroll, Complete Works, p. I34. 